Revista Brasil. Bot., V.32, n.2, p.339-348, abr.-jun. 2009

\title{
Anatomia de folha e caule e quantificação espectrofotométrica de fenóis totais e taninos da erva-de-bicho (Polygonum acre Kunth var. aquatile Meisn.) ${ }^{1}$
}

\author{
SHARON SANTOS DE LIMA ${ }^{2,5}$, ELIANA SCHWARTZ TAVARES ${ }^{2,3}$, \\ DAVYSON DE LIMA MOREIRA ${ }^{4}$, GILDA GUIMARÃES LEITÃO ${ }^{4}$ \\ e MARIA APPARECIDA ESQUIBEL ${ }^{2}$
}

(recebido: 4 de julho de 2007; aceito: 11 de março de 2009)

\begin{abstract}
Leaf and stem anatomy and spectrophotometric quantification of total phenolics and tannins of erva-de-bichoPolygonum acre Kunth var. aquatile Meisn.). Polygonum acre Kunth var. aquatile Meisn., a medicinal plant, was studied with the purpose of selecting useful characteristics for fragmented plant identification as well as to contribute to the botanical study of the species. Usual anatomical analysis was used and total phenolics, condensed and galic tannins were quantified. The comparison with bibliographic data allowed to select some characteristics to help the identification of $P$. acre: 1) absence of well defined endodermis with Casparian strips on the stem in accordance with others species of the Polygonum genus; 2) numerous multicellular trichomes on the ocrea and secretory cavities only in abaxial epidermis; 3 ) fibers on the interior of the xylem from the stem; 4) inverted bundle in midrib and 5) lignified protuberances in the edge of the leaf. The quantification of total phenolics and tannins from $P$. acre shows remarkable amounts of condensed tannins, but no hydrolysable tannins were detected.
\end{abstract}

Key words - condensed tannins, erva-de-bicho, medicinal plant, pharmacognosy, Polygonaceae

RESUMO - (Anatomia de folha e caule e quantificação espectrofotométrica de fenóis totais e taninos da erva-de-bicho Polygonum acre Kunth var. aquatile Meisn.). Com o objetivo de selecionar caracteres úteis na identificação de Polygonum acre Kunth var. aquatile Meisn., erva medicinal geralmente comercializada sob a forma de planta fragmentada, e para contribuir para o conhecimento botânico da espécie, descreveu-se sua anatomia e quantificaram-se os fenóis totais, taninos gálicos e condensados. O material foi processado segundo técnicas usuais de anatomia vegetal. Na análise anatômica, a comparação dos resultados com a bibliografia permitiu selecionar os seguintes caracteres como auxiliares à determinação de P. acre: 1) ausência de endoderme bem definida com estrias de Caspary conforme descrito para outras espécies do gênero Polygonum; 2) ócrea com numerosos tricomas pluricelulares e cavidades secretoras localizadas apenas na face abaxial da epiderme; 3) fibras presentes internamente ao xilema do caule; 4) feixe invertido na nervura principal; e 5) presença de pêlos lignificados no bordo da folha. As dosagens de fenóis totais e taninos demonstraram que a planta apresenta quantidade significativa de taninos condensados e que a princípio, os taninos gálicos não estão presentes na espécie.

Palavras-chave - erva-de-bicho, farmacognosia, plantas medicinais, Polygonaceae, taninos condensados

\section{Introdução}

Polygonum acre Kunth var. aquatile Meisn. Polygonaceae (Meisner 1855) é planta nativa, popularmente conhecida como erva-de-bicho ou pimenta-d'água (Joly

1. Parte da dissertação de mestrado da primeira autora, Programa de Pós-Graduação em Biotecnologia Vegetal da Universidade Federal do Rio de Janeiro.

2. Universidade Federal do Rio de Janeiro, Instituto de Biofísica Carlos Chagas Filho, Laboratório de Fisiologia Vegetal, Bloco G, CCS, Cidade Universitária, 22949-900 Rio de Janeiro, RJ, Brasil.

3. Universidade Federal do Rio de Janeiro, Instituto de Biologia, Laboratório de Anatomia Vegetal, Bloco A, CCS, Cidade Universitária, 22949-900 Rio de Janeiro, RJ, Brasil.

4. Universidade Federal do Rio de Janeiro, Núcleo de Pesquisas de Produtos Naturais, Bloco H, CCS, Cidade Universitária, 22949900 Rio de Janeiro, RJ, Brasil.

5._Autor para correspondência: sharonsl@biof.ufrj.br
1976, Teixeira et al. 1989). Vegeta preferencialmente em lugares úmidos, em brejos de água corrente e na beira de rios (Pio Corrêa 1984), ocorrendo na costa leste sulamericana. É uma erva perene, que pode alcançar até $1 \mathrm{~m}$ de altura. O caule é formado por nós e entrenós bem nítidos e avermelhados, o perigônio é coberto por glândulas escuras visíveis a olho nu, a ócrea é cilíndrica e bastante ciliada na margem. As flores são bissexuadas, pentâmeras, monoclamídeas, actinomorfas, brancas ou róseas e ficam reunidas em inflorescência do tipo espiga (Meisner 1855, Pio Corrêa 1984).

Polygonum acre tem emprego medicinal sendo utilizada no tratamento de má circulação, varizes, úlceras varicosas, hemorróidas, e no combate à sarna (Teixeira et al. 1989). Os estudos farmacológicos realizados com P. acre não são acompanhados por estudos fitoquímicos, 
sendo feitas apenas algumas inferências que relacionam as ações biológicas à presença de taninos e flavonóides (Joachimovits 1959, Simões et al. 1989, Teixeira et al. 1989, Freixa et al. 1998, Kott et al. 1999). Suas folhas e caules são a matéria-prima para a fabricação de fitoterápicos, geralmente apresentados na forma de supositórios ou cremes. O uso de plantas como matériaprima para medicamentos envolve alguns aspectos críticos, dentre eles o fato de serem comuns as adulterações e o uso de espécie incorreta devido ao desconhecimento ou a insuficiência e imprecisão dos caracteres diagnósticos descritos para a espécie. Problemas como estes comprometem a qualidade e a eficácia dos medicamentos assim como a segurança dos consumidores (Melo et al. 2004). Estudos anatômicos associados a fitoquímicos geram subsídios importantes, frequientemente empregados no reconhecimento e controle de qualidade da matéria-prima vegetal. Apesar de serem poucos os estudos anatômicos realizados para a família Polygonaceae, trabalhos como os de Mitchell (1971), Lersten \& Curtis (1992) e Silva-Brambilla \& Moscheta (2001) descrevem a anatomia foliar de diversas espécies do gênero Polygonum, enquanto Zhu et al. (2007a, b) e Lu et al. (2007) descrevem a epiderme de diferentes seções de Polygonum. O presente trabalho enfocou aspectos anatômicos da folha e pela primeira vez da composição química da folha e caule, bem como anatomia do caule de Polygonum acre, por serem estas as partes comercializadas para fins terapêuticos. A presença de fenóis totais e taninos na planta também foi investigada, buscando contribuir para o estudo farmacognóstico e o controle de qualidade do comércio e industrialização desta espécie.

\section{Material e métodos}

A coleta do material vegetal foi realizada na Fazenda Bom Jardim, em Muriaé, Minas Gerais. A confirmação da espécie foi feita pela Professora $\operatorname{Dr}^{\mathrm{a}}$ Cecília Maria Rizzini do Instituto de Biologia/CCS/UFRJ. A exsicata encontra-se depositada no herbário do Instituto de Biologia/CCS/UFRJ sob o registro RFA23928.

Em todas as etapas do presente estudo foram utilizadas triplicatas de material botânico. Para o estudo histológico e histoquímico de $P$. acre foram usadas plantas com 6 meses de cultivo. Para estudo histológico, após coleta as plantas foram conservadas em álcool etílico $70 \%$. Foram confeccionadas lâminas semi-permanentes de folhas provenientes do $5^{\circ}$ nó e de caule do $5^{\circ}$ e do $9^{\circ}$ entrenós, a contar do ápice para a base. Foram efetuadas secções transversais do pecíolo, da lâmina foliar e da ócrea, todos na região mediana, com auxílio de micrótomo de Ranvier. A epiderme foi retirada mecanicamente com o uso de lâmina de barbear (Kraus \& Arduin 1997).
Para coloração dos cortes transversais, foi utilizada mistura de safranina com azul de astra, segundo formulação de Bukatsch (1972). A coloração da epiderme foi realizada com safranina-hidroalcoólica (Strasburger 1924). As lâminas foram montadas em glicerina:água $(1: 1, \mathrm{v} / \mathrm{v})$ e lutadas com esmalte incolor. O material foi observado e fotomicrografado ao microscópio Axiovert 100 Zeiss.

Testes foram realizados em cortes de material recém coletado, feitos à mão livre. A detecção de substâncias fenólicas foi realizada pelo teste de Hoepfner-Vörsatz (Johansen 1940), de substâncias lipídicas pelo sudan IV (Johansen 1940), para grau de lignificação das paredes utilizou-se floroglucinol em meio ácido (Sass 1951), e para grãos de amido o teste com lugol (Johansen 1940). A natureza química dos cristais de oxalato de cálcio foi confirmada através de insolubilidade em ácido acético e solubilidade em ácido clorídrico (Maclean \& Ivemey-Cook 1958). Como branco dos testes microquímicos foram utilizados cortes sem qualquer tratamento. Para a diafanização das folhas, o material fixado em álcool etílico $70 \%$ foi clarificado em solução de água sanitária 50\%, neutralizado em água acidulada e desidratado em série etanólica ascendente $(50 \%, 70 \%, 80 \%, 90 \%$ e $100 \%, 30$ minutos em cada solução). Depois de corado com safranina alcoólica por $24 \mathrm{~h}$, o material foi diferenciado pela série álcool etílico:xilol (3:1, 1:1 e 1:3 e xilol absoluto, 24 horas em cada solução) e por fim, montado em resina sintética Entellan.

Foi realizada a quantificação espectrofotométrica dos fenóis totais, taninos condensados e taninos gálicos, segundo os métodos descritos por Waterman \& Mole (1994). Para esse ensaio, partes aéreas inteiras, porém sem flores ou frutos, de plantas monoclonais aclimatadas em Muriaé/MG (Lima et al. 2001) foram coletadas no mês de maio. Dessas amostras liofilizadas e trituradas, foram usados $500 \mathrm{mg}$ em cada ensaio, realizados sempre em triplicata. A quantificação dos fenóis totais e dos taninos foi feita por espectrofotometria na região do UV/ VIS (Shimadzu, modelo 1601) pelo método de FolinDenis, proantocianidinas e rodanina, respectivamente (Waterman \& Mole 1994). Amostras de origem comercial de pedúnculo de caju (Anacardium occidentale L. Anacardiaceae), folhas de chá verde (Camellia sinensis (L.) Kuntze - Theaceae) e folhas de hamamelis (Hamamelis virginiana L. - Hamamelidaceae) foram analisadas quanto aos teores de taninos condensados e gálicos, segundo os métodos supracitados para efeito de comparação. Os resultados da quantificação espectrofotométrica de polifenóis foram submetidos ao teste de T de Tukey $(P<0,001)$, efetuadas pelo software Graph Pad InStat, versão 3.01.

\section{Resultados e discussão}

Anatomia e microquímica - O caule é revestido por epiderme unisseriada recoberta por cutícula lisa. Nesta epiderme, estão presentes tricomas glandulares plurisseriados cujas células encontram-se alongadas no sentido perpendicular ao órgão (figura 1). A base destes 
tricomas é constituída por duas células com paredes anticlinais espessadas que, quando juntas, têm a forma de um trapézio. O córtex é constituído por colênquima lacunar e, mais internamente, por parênquima com grandes espaços intercelulares. As drusas são numerosas tanto no córtex quanto na medula. Os diagramas que esquematizam a organização dos tecidos observada no caule, no 5 e 9o entrenós, podem ser vistos nas figuras 2 e 3 , respectivamente.

O sistema vascular está disposto em cilindro e é constituído por feixes do tipo colateral aberto. Na altura do $9^{\circ}$ entrenó, são encontradas camadas de fibras externamente ao floema e internamente ao xilema (figura 3), complementando observações de Metcalfe \& Chalk (1950) para o gênero Polygonum, pois estes descreveram fibras acompanhando apenas o floema. A região correspondente à parte externa da medula é formada por parênquima com espaços intercelulares e no interior destas células há numerosos grãos de amido. Comumente, a região central da medula é oca. Segundo Metcalfe \& Chalk (1950) o caule das espécies de Polygonum apresenta endoderme bem definida, porém esta característica não foi observada em Polygonum acre. Metcalfe \& Chalk (1950) caracterizaram a endoderme bem definida como uma camada de células que diferem de suas vizinhas pela presença de amido, pelo espessamento de Caspary ou por serem suberizadas. Nenhuma destas características foi encontrada na espécie em estudo.

Polygonum acre é comprovadamente produtora de substâncias fenólicas. Os testes microquímicos realizados com cortes do caule evidenciaram a presença de conteúdo marrom gelatinoso no tecido parenquimático e no floema, tantos nos elementos de tubo crivado quanto nas células parenquimáticas, caracterizando positivamente a existência desta classe química na planta, como descrito por Metcalfe \& Chalk (1950) e por Joachimovits (1959) para Polygonum sp. No caule, o teste para substâncias fenólicas também foi positivo na epiderme, no colênquima angular, no parênquima do xilema mais próximo à medula e nos tricomas glandulares. O conteúdo das cavidades secretoras junto à epiderme apresentou coloração positiva para a presença de substâncias lipídicas.

Em secções transversais da região mediana da ócrea foi observado que a epiderme, tanto da face adaxial quanto da face abaxial é unisseriada. As camadas subepidérmicas da face abaxial constituem colênquima lacunar. $\mathrm{O}$ parênquima fundamental apresenta espaços intercelulares nas porções mais largas da ócrea. Estão presentes feixes vasculares do tipo colateral envoltos por uma bainha de fibras. As drusas aparecem em grande número (figura 4), assim como os tricomas glandulares pluricelulares alongados como os já descritos (figura 1). As ócreas raramente são descritas, portanto, pouco se sabe sobre o tipo e a distribuição de tricomas nestas estruturas. Lersten \& Curtis (1992) observaram tricomas multicelulares em ócreas de poucas espécies de Polygonaceae, conferindo a eles a característica de provavelmente secretarem a mucilagem que intumesce e cobre os nós de algumas espécies durante o período de chuvas. Cavidades secretoras designadas por Mitchell (1971) como câmaras valvares, foram descritas como o tipo glandular mais complexo encontrado apenas em folhas das espécies $P$. punctatum Ell. (sinônimo de $P$. acre Kunth), $P$. densiflorum Meisn. e P. robustius Fern. Essas cavidades secretoras são numerosas na epiderme da face abaxial da ócrea (figura 5).

$\mathrm{Na}$ ócrea, o teste para substâncias fenólicas foi positivo na epiderme, em todo o floema, nos tricomas glandulares pluricelulares e no parênquima do xilema. O teste para substâncias lipídicas foi positivo no conteúdo das cavidades secretoras.

A secção transversal do pecíolo na região mediana é plano-convexa (figura 6). A epiderme é unisseriada (figura 7) revestida por uma cutícula fina, apresentando tricomas glandulares e cavidades secretoras como já descritos para o caule e ócrea, respectivamente, além de tricomas tectores pluricelulares com ápice agudo e paredes fortemente espessadas e lignificadas. Em posição subepidérmica está presente o colênquima intermediário entre os tipos lacunar e angular, sob o qual está o parênquima fundamental com células dotadas de espaços intercelulares (figura 7), conforme descrito por Machado (1949) em um breve estudo histológico desta espécie. O sistema vascular está distribuído em forma de meia lua (figura 6) com feixes do tipo colateral (figura 8) distantes entre si (figura 6). Esta disposição dos feixes vasculares também foi descrita para o gênero Polygonum por Metcalfe \& Chalk (1950). Foram evidenciados frequientes idioblastos contendo drusas em todos os cortes observados. Os cristais de oxalato de cálcio são substâncias largamente distribuídas nas angiospermas. Estes cristais podem assumir várias formas e são usados como caráter taxonômico. Segundo Metcalfe (1979), os cristais de oxalato de cálcio do tipo drusa são particularmente numerosos no gênero Rheum (Polygonaceae). Nos cortes histológicos de $P$. acre foram encontradas muitas drusas no caule, na ócrea, no mesofilo e na nervura principal.

A epiderme da lâmina foliar, em vista frontal, apresenta células com paredes anticlinais retas na face adaxial e levemente sinuosas na face abaxial (figuras 9 e 10). Em ambas as faces estão presentes estômatos paracíticos e raramente anisocíticos, sendo a espécie 


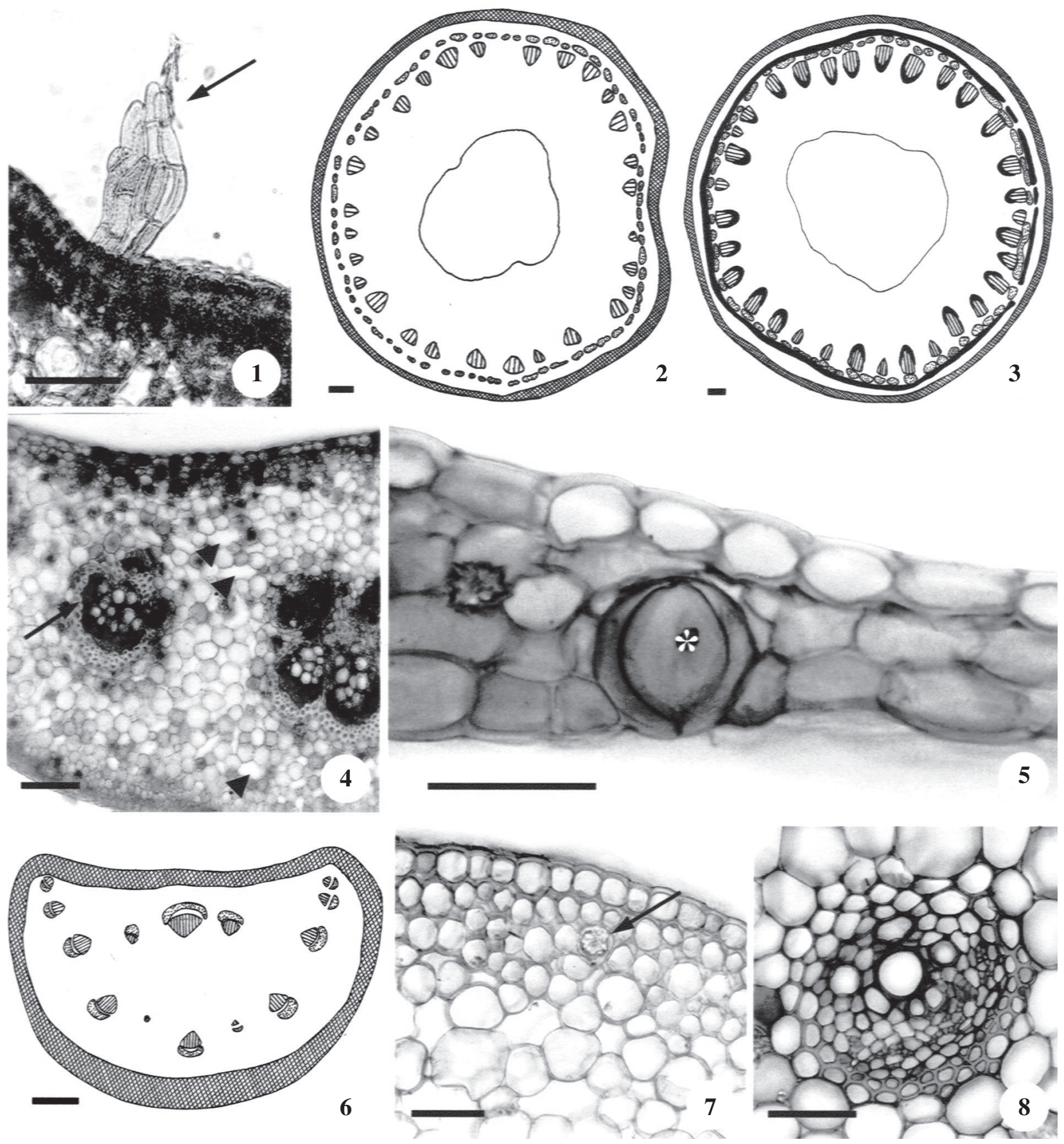

Figuras 1-8. 1. Secção transversal de caule do 5o entrenó. Tricoma glandular plurisseriado (seta). 2. Diagrama da secção transversal do caule no 5o entrenó. 3. Diagrama da secção transversal do caule no 9o entrenó. Presença de fibras pericíclicas. 4. Secção transversal da região mediana da ócrea, onde se evidenciam espaços intercelulares em sua porção mais larga (cabeças de seta), feixes vasculares do tipo colateral (seta) e diversas drusas. 5. Secção transversal da região mediana da ócrea onde se evidencia uma cavidade secretora $(*)$ na epiderme abaxial. 6. Diagrama da secção transversal da região mediana do pecíolo. 7. Detalhe da secção transversal da região mediana do pecíolo. Colênquima intermediário entre os tipos lacunar e angular e parênquima fundamental com espaços intercelulares; a seta indica uma drusa. 8. Detalhe do feixe vascular encontrado em secção transversal da região mediana do pecíolo. Barra $=50 \mu \mathrm{m}(1,4,5,7,8) ; 200 \mu \mathrm{m}(2,3,6)$. (图 = colênquima; $\square=$ floema; $\boldsymbol{\square}$ = fibras; $\mathbf{m}$ = xilema; $\square=$ parênquima). 
anfiestomática. Quanto aos tipos de estômatos que ocorrem em Polygonum, a bibliografia consultada mostra ser comum a ocorrência de estômatos paracíticos e anisocíticos (Mitchell 1971, Lersten \& Curtis 1992) e menos freqüente a de estômatos anomocíticos (Mitchell 1971, Silva-Brambilla \& Moscheta 2001). Foi observado também que diferentes populações de uma mesma espécie podem apresentar variação quanto aos tipos de estômatos (Mitchell 1971). Isso parece ocorrer com relação a $P$. acre, já que Silva-Brambilla \& Moscheta (2001) descreveram estômatos anomocítios que não foram observados no presente trabalho. No gênero Polygonum existe uma considerável variação de tipos de estômatos entre as espécies de modo que não existem padrões úteis taxonomicamente, assim como, não existem padrões coerentes de distribuição de estômatos entre as faces adaxial e abaxial (Lersten \& Curtis 1992). Contudo, Mitchell (1971) descreveu que estômatos paracíticos e anisocíticos ocorriam juntos apenas em folhas de $P$. punctatum $(=P$. acre) que também possuíam grandes idioblastos presentes na epiderme da face superior. Segundo suas observações, as populações de $P$. punctatum que não possuíam os idioblastos, apresentavam apenas estômatos paracíticos. Os grandes idioblastos descritos por Mitchell (1971) não foram observados na planta em estudo, porém ambos tipos de estômatos (paracíticos e anisocíticos) foram evidenciados. Foram encontrados tricomas glandulares que exibem cabeça pluricelular de contorno circular, sempre apresentando quatro células (figuras 9 e 10). A base do tricoma é circundada por seis células epidérmicas propriamente ditas (figura 9). Observam-se ainda em ambas as faces cavidades secretoras. As células epiteliais que estão voltadas para o exterior da folha são em numero de quatro (figura 11). Os tricomas glandulares capitados são descritos por Mitchell (1971) e Lersten \& Curtis (1992) como amplamente distribuídos em Polygonaceae, especialmente em Polygonum. A cavidade secretora também foi descrita por Lersten \& Curtis (1992) para 10 espécies da seção Persicaria, que inclui $P$. acre.
Secções transversais da lâmina na região entre a nervura e o bordo evidenciaram epiderme unisseriada (figura 12) revestida por cutícula rugosa na face adaxial e lisa na abaxial, característica também observada em P. plebeium R. Br. (Metcalfe \& Chalk 1950). No mesofilo estão presentes idioblastos com drusas (figura 12). O mesofilo é do tipo dorsiventral, com uma a duas camadas de parênquima paliçádico e cerca de três camadas de parênquima lacunoso (figura 12). Silva-Brambilla \& Moscheta (2001) observaram de duas a três camadas de parênquima paliçádico e de quatro a cinco camadas de parênquima lacunoso em $P$. punctatum $(=P$. acre) coletado na planície de inundação do alto Rio Paraná, porém as estruturas epidérmicas e as camadas do mesofilo podem sofrer alterações em resposta ao ambiente em que ocorrem (Schlichting 1986). As características evidenciadas nas camadas do mesofilo de $P$. acre estão em conformidade com o que é comumente observado em Polygonaceae (Metcalfe \& Chalk 1950). Os tricomas glandulares capitados bem como as cavidades secretoras estão localizados em ligeiras depressões da epiderme (figuras 13 e 14). Nas regiões adjacentes às cavidades secretoras, as células parenquimáticas dão lugar a células epiteliais estreitas com paredes mais espessadas (figura 13). Segundo Metcalfe \& Chalk (1950), cavidades secretoras circundadas por células epiteliais estreitas, visíveis no perigônio como pontos de coloração diferenciada, ocorrem em poucas espécies de Polygonum. Essas mesmas cavidades foram descritas por Pio Corrêa (1984) como "glândulas escuras visíveis a olho nu", característica utilizada para diferenciar $P$. acre de $P$. hydropiper L. As nervuras de pequeno calibre são constituídas de feixes colaterais envolvidas por bainha parenquimática (figura 12). As estruturas da epiderme e das camadas do mesofilo evidenciadas em $P$. acre são corroboradas pelo trabalho realizado por SilvaBrambilla \& Moscheta (2001).

Na região do bordo, as paredes das células epidérmicas são mais espessas e o parênquima clorofiliano está constituído por células de secção transversal arredondada

Figures 1-8. 1. Cross section of the stem on 5th internode. Pluriseriate glandular trichome (arrow). 2. Cross section diagram of the stem on $5^{\text {th }}$ internode. 3. Cross section diagram of the stem on $9^{\text {th }}$ internode. Note the pericycle fibers. 4 . Cross section from median region of the ocrea, showing intracellular spaces at its widest portion (arrowhead), collateral vascular bundles (arrow) and several druses. 5. Cross section from median region of the ocrea showing a secretory cavity ( $*$ ) on abaxial epidermis. 6. Cross section diagram from median region of the petiole. 7. Detail of cross section from median region of petiole. Collenchyma, which is intermediary between lacunar and angular shapes, and fundamental parenchyma showing intercellular spaces; the arrow indicates a druse. 8. Detail of the vascular bundle found in cross section from the median region of the petiole. $\operatorname{Bar}=50 \mu \mathrm{m}(1,4,5,7,8) ; 200 \mu \mathrm{m}(2,3,6)$. (圂 = collenchyma; $\mathbf{\square}=$ phloem; $\mathbf{\square}=$ fibers; 血=xylem; $\square=$ parenchyma). 


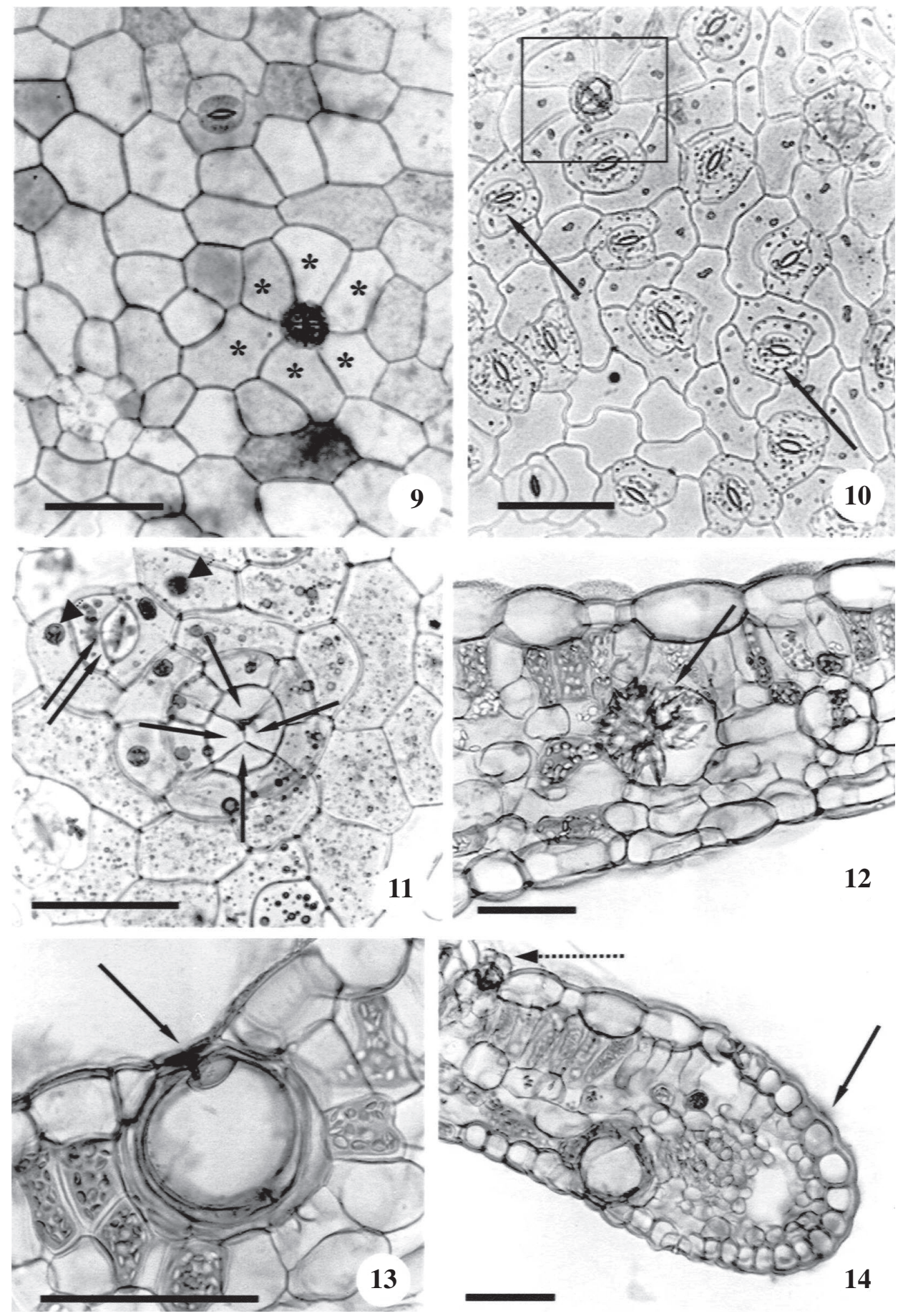

Figuras 9-14. 9. Face adaxial da epiderme foliar com células de paredes anticlinais retas. As marcações (*) na figura mostram as seis células que circundam o tricoma glandular de cabeça pluricelular e contorno arredondado. 10. Face abaxial da epiderme foliar com células de paredes anticlinais levemente sinuosas. As setas indicam estômatos paracíticos. Na área delimitada pelo quadrado observa-se o tricoma glandular. 11. Face adaxial da epiderme foliar com detalhe da cavidade secretora. As setas indicam as quatro células que constituem a superfície da cavidade. A seta dupla indica estômato paracítico. As cabeças de seta indicam gotículas de substâncias lipídicas, presentes no interior das células da epiderme, as quais coram fortemente com sudan IV. 12. Secção transversal da folha mostrando parênquima paliçádico com 1-2 camadas de células e parênquima lacunoso com 2-3 camadas de células. Idioblasto com drusa (seta). 13. Cavidade secretora da folha. A seta indica a depressão da epiderme que dá lugar a superfície da cavidade e as células epidérmicas espessadas que a circundam. 14. Secção transversal da folha na região do bordo. Espessamento das paredes das células epidérmicas (seta) e tricoma glandular capitado (seta pontilhada). Barra $=50 \mu \mathrm{m}$. 
(figuras 14 e 15). De forma intermitente, porém por todo o bordo, são observados pêlos lignificados definidos por Meisner (1855) como "margine constanter ciliolatoscabriusculo" - margem com cílios escabrosos constantes (figuras 15 e 16). A figura 15 apresenta uma secção transversal que inclui a base de um desses pêlos. SilvaBrambilla \& Moscheta (2001) descreveram esses pêlos como "pêlos tectores aglomerados, longos e bastante inclinados, rentes à superfície”. Segundo Mitchell (1971), membros do complexo $P$. punctatum tendem a apresentar as folhas glabras com tricomas concentrados ao longo da nervura mediana e bordos foliares. Da mesma forma que Silva-Brambilla \& Moscheta (2001), Lersten \& Curtis (1992) e Mitchell (1971) não fizeram menção à lignificação.

A nervura principal na região mediana da lâmina exibe secção transversal convexo-convexa (figura 17). As células epidérmicas mostram secção transversal arredondada (figura 17) revestida por cutícula espessa. Em posição subepidérmica na face abaxial ocorre o colênquima do tipo intermediário entre lacunar e angular (figura 18), e na face adaxial o colênquima é do tipo angular (figura 17). O parênquima paliçádico é interrompido apenas na região central da nervura (figura 17). O tecido vascular forma um anel de feixes colaterais (figura 17), protegidos por fibras externas ao floema e não em ambos os lados do feixe vascular como ocorre em outras espécies de Polygonum (Metcalfe \& Chalk 1950). Na região adaxial da nervura encontra-se um feixe invertido (figura 17). Envolvendo os feixes encontra-se parênquima fundamental que apresenta lacunas, principalmente na face abaxial. Nesse parênquima são observados diversos idioblastos com drusas (figura 17).

No terço médio da folha do 5o nó da planta, houve reação positiva para substâncias fenólicas na epiderme, inclusive nos tricomas glandulares plurisseriados, no floema e no parênquima do xilema. O conteúdo das cavidades secretoras e dos tricomas glandulares capitados coraram de vermelho forte, indicando a presença de substâncias lipídicas, como já observado nesta espécie (Lersten \& Curtis 1992, Silva-Brambilla \& Moscheta 2001). Foram observadas diversas gotículas de substância lipídica próximas às cavidades secretoras (figura 11).

Quantificação espectrofotométrica dos fenóis totais e taninos - O teste de Hoepfner-Vörsatz (Johansen 1940) realizado nas secções histológicas da folha e do caule da planta apresentaram coloração intensa indicando a presença de substâncias fenólicas. Apesar de a erva-debicho ser uma planta medicinal nativa de uso freqüente pela população e parte de suas propriedades terapêuticas estarem relacionadas à presença de taninos (Simões et al. 1989, Almeida et al. 1995), não existem estudos sobre esta classe química nesta planta.

$\mathrm{O}$ teor de fenóis totais encontrado nas amostras analisadas foi de $1,57 \%$ ( $\pm 0,05 \%$ - média \pm erro padrão $)$ e o teor de taninos condensados foi de 7,20\% ( $\pm 0,27 \%$ - média \pm erro padrão). Taninos gálicos não foram detectados pelo método utilizado (rodanina, segundo Waterman \& Mole 1994). De fato, os taninos condensados estão amplamente distribuídos no Reino Vegetal, enquanto os taninos gálicos, também conhecidos como taninos hidrolisáveis, são de distribuição mais restrita, ocorrendo dentro de limites taxonômicos bem definidos em dicotiledôneas herbáceas e lenhosas, a ponto dos taninos elágicos (tipo especial de taninos hidrolisáveis) serem usados como marcadores taxonômicos, devido à sua distribuição em Hamamelidae, Dilleniidae e Rosidae (Kubitzki \& Gottlieb 1984, Bruyne et al. 1999).

O teor de taninos condensados observado para a erva-de-bicho foi superior apenas àquele observado para hamamelis (figura 19). O caju e o chá verde são conhecidamente produtores de taninos. Os taninos condensados promovem adstringência que representa uma limitação comercial para o caju (Agostini-Costa $e t$ al.2003). No chá verde, taninos condensados e hidrolisáveis estão relacionados aos seus efeitos medicinais (Schmitz et al. 2005). Os taninos gálicos foram detectados tanto

Figures 9-14. 9. Adaxial surface of leaf epidermis presenting cells with walls straight anticlinal. The six cells surrounding the glandular trichome of pluricellular head and rondure are marked by asterisks $(*)$. 10. Abaxial surface of leaf epidermis presenting cells with walls slightly sinuous. The arrows indicate paracytic stomata. In the area bounded by the square there is a glandular trichome. 11. Adaxial surface of leaf epidermis showing detail of secretory cavity. The four cells that form the cavity surface are indicate by arrows. The double arrow indicate the paracytic stomatal. The arrowhead indicate lipidic droplets into the epidermal cells, which strongly stain with sudan IV. 12. Cross section of the leaf showing palisade parenchyma with 1-2 layers of cells and lacunary parenchyma with 2-3 layers of cells. Idioblast containing druse (arrow). 13. Secretory cavity of the leaf. The arrow indicate the depression in cavity surface and the thickening epidermal cells that form the cavity. 14. Cross section of the leaf in the margin region. Epidermal cells thickning (arrow) and glandular capitate trichome (dotted arrow). Bar $=50 \mu \mathrm{m}$. 

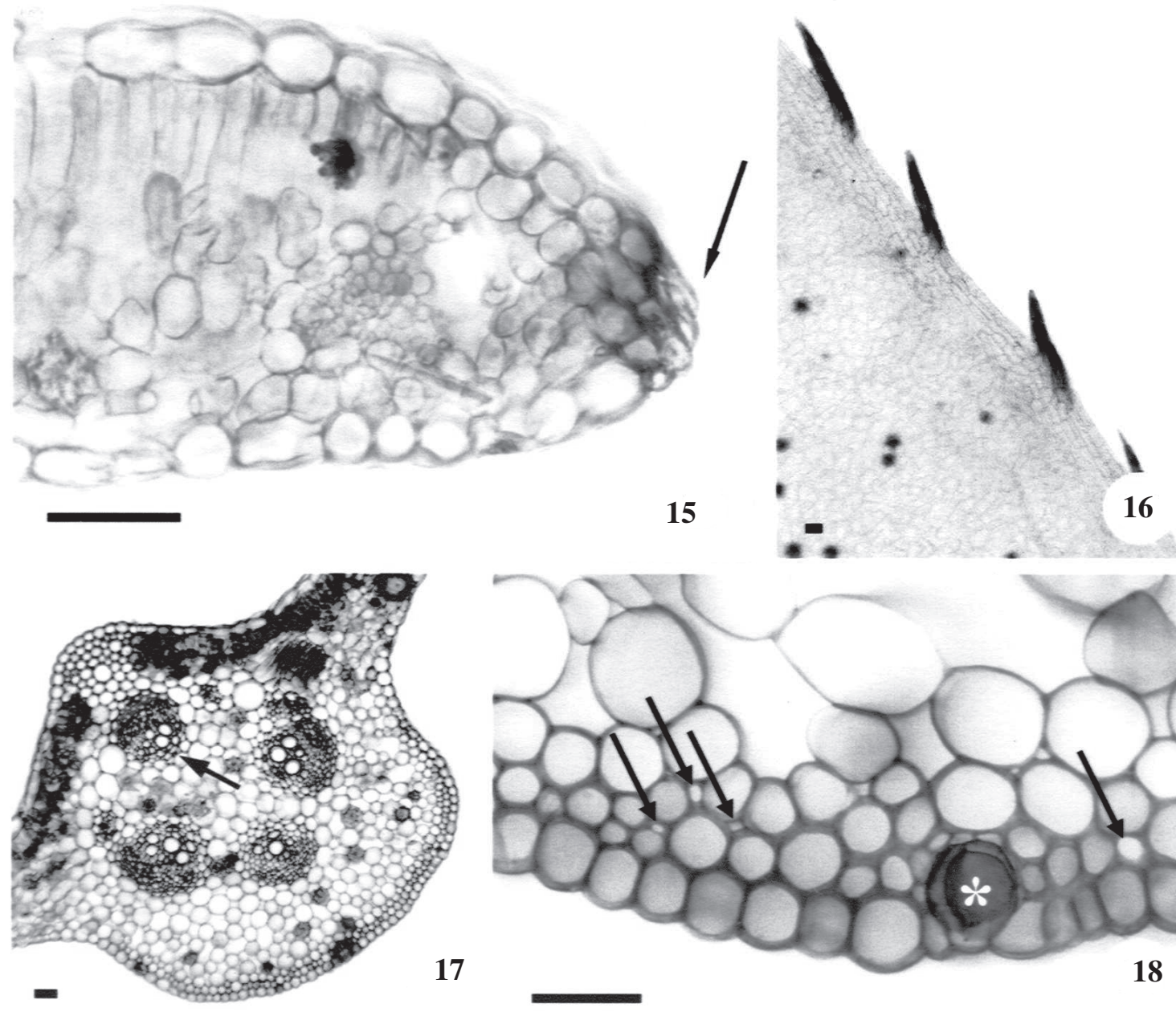

17

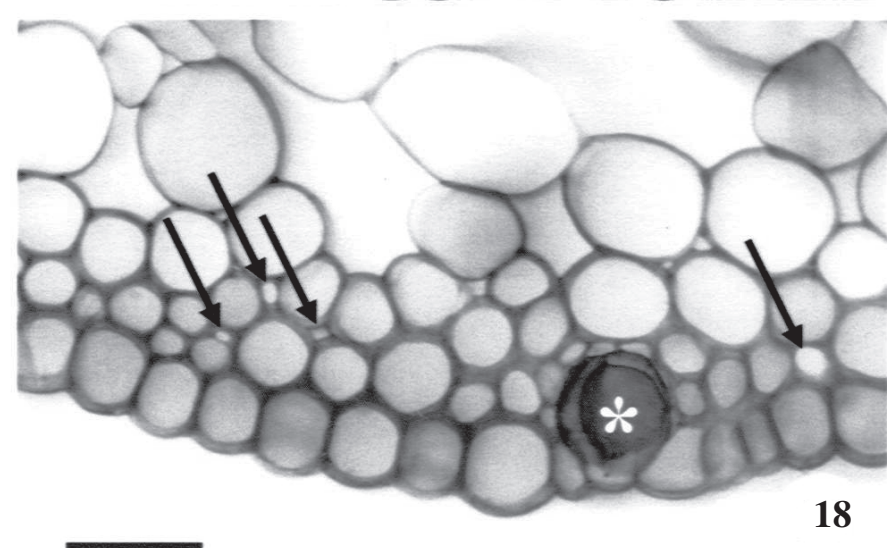

Figuras 15-18. 15. Secção transversal da folha na região do bordo. A seta indica células lignificadas da base do pêlo que ocorre no bordo. 16. Vista frontal do bordo da folha diafanizada onde se evidenciam os pêlos com células lignificadas. 17. Nervura principal na região mediana da folha em seç̧ão transversal: feixe invertido (seta). 18. Detalhe da face abaxial da nervura principal na região mediana da folha em secção transversal onde pode ser observado o colênquima do tipo intermediário entre lacunar e angular. Lacunas (setas) e cavidade secretora $(*)$. Barra $=50 \mu \mathrm{m}$.

Figures 15-18. 15. Cross section of leaf margin. The arrow indicate lignified cells at the base of the hair that occurs on margin. 16. Front view of the diafanized leaf margin showing hairs with lignified cells. 17. Cross section of the midvein in median region of the leaf: inverted bundle (arrow). 18. Abaxial surface detail of midvein in median region of the leaf in cross section showing colenchyma between lacunar and angular shapes. Intercellular spaces (arrow) and secretory cavity (*). Bar $=50 \mu \mathrm{m}$.

na amostra de caju quanto nas amostras de chá verde e hamamelis, mas não na erva-de-bicho (figura 19). A ocorrência de taninos hidrolisáveis é bem descrita para hamamelis, sendo a estes atribuídas as propriedades medicinais da planta (Blumenthal et al. 1998, Newall et al. 2002).

Certamente, os teores encontrados para fenóis totais e taninos condensados não são fixos. Como as plantas, que apesar de imóveis são organismos dinâmicos, o esperado é que o acúmulo de polifenóis varie ao longo das estações do ano, pois o conteúdo polifenólico é dependente de fatores intrínsecos (genéticos) e extrínsecos - ambientais (Fratianni et al. 2007) variando diante de diversas situações, como o tipo de órgão da planta (Falleh et al. 2008), fase do desenvolvimento vegetal (Schweitzer et al. 2008), local de cultivo ou ocorrência e entre as diferentes estações do ano (Bussotti et al. 1998, Ma et al. 2003, Brooks \& Feeny 2004). As variações do conteúdo polifenólico são definidas por base genética que é fortemente afetada pelas condições seja do ambiente 


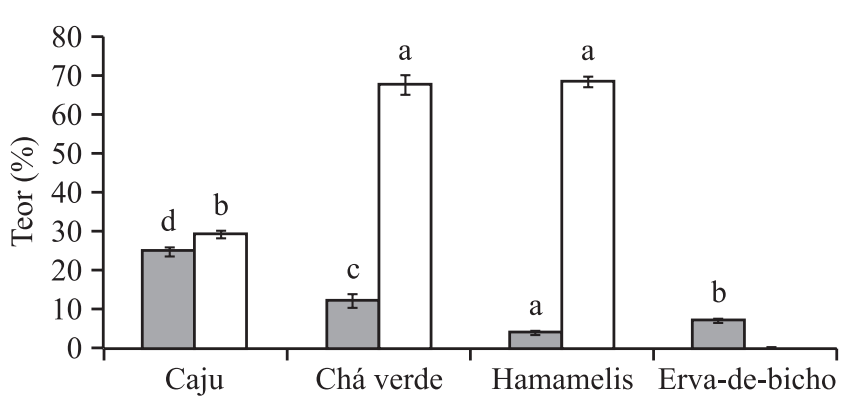

Figura 19. Teores de taninos condensados $(\square)$ e taninos gálicos $(\square)$ encontrados em amostras de caju, chá verde, hamamelis e erva-de-bicho. Média \pm erro padrão. Letras iguais, para o mesmo item analisado indicam igualdade estatística quando $P>0,001$.

Figure 19. Percentage of condensed tannins $(\square)$ and galic tannins $(\square)$ found in caju, chá verde, hamamelis and ervade-bicho samples. Mean \pm SD. Same letters, for the same item analyzed, indicate statistic equality for $P>0,001$.

natural ou de cultivo (Conde et al. 2008). Dessa forma, os raros estudos sobre variação sazonal de polifenóis têm indicado que as alterações climáticas que ocorrem ao longo do ano, principalmente aquelas relacionadas à quantidade de precipitação e variação de temperatura, induzem alterações no fenótipo da planta que altera seu padrão de produção de polifenóis para se adequar a cada situação, como excesso ou carência de água (Ma et al. 2003, Brooks \& Feeny 2004). As implicações ecológicas das variações do padrão de produção de polifenóis, mais especificamente de taninos condensados, são inúmeras e pouco compreendidas (Bailey et al. 2006, Schweitzer et al. 2008).

De acordo com os resultados, as seguintes características são destacadas como úteis para identificação da planta: $1^{\circ}$ ) ausência de endoderme bem definida com estrias de Caspary; $2^{\circ}$ ) ócrea com numerosos tricomas pluricelulares e cavidades secretoras localizadas apenas na face abaxial da epiderme; $3^{\circ}$ ) fibras presentes internamente ao xilema do caule; $4^{\circ}$ ) feixe invertido na nervura principal; e 5은 presença de pêlos lignificados no bordo da folha. Segundo os métodos adotados para quantificação espectrofotométrica dos taninos e fenóis totais, $P$. acre apresenta quantidades razoáveis de taninos condensados e fenóis totais, enquanto os taninos gálicos podem estar completamente ausentes nesta planta ou em quantidades não detectáveis pelo método utilizado. Os dados aqui descritos trazem contribuições farmacognósticas relevantes que podem ser aplicadas em plantas utilizadas como matéria-prima para a fabricação de fitoterápicos.
Agradecimentos - Os autores agradecem aos proprietários da Fazenda Bom Jardim (Muriaé - MG), onde as plantas utilizadas neste estudo foram coletadas, e à Capes pelo auxílio financeiro.

\section{Referências bibliográficas}

AGOSTINI-COSTA, T.S., LIMA, A. \& LIMA, M.V. 2003. Determinação de tanino em pedúnculo de caju: método da vanilina versus método do butanol ácido. Química Nova 26:763-765.

ALMEIDA, C.E., KARNNIKOWISK, M.G.O., FOLETO, R. \& BALDISSEROTTO, B. 1995. Analysis of antidiarrhoeic effect of plants used in popular medicine. Revista de Saúde Pública 29:428-433.

BAILEY, J.K., WOOLEY, S.C., LINDROTH, R.L. \& WHITHAM, T.G. 2006. Importance of species interactions to community heritability: a genetic basis to trophic-level interactions. Ecology Letters 9:78-85.

BLUMENTHAL, M., BUSSE, W.R., GOLDBERG, A., GRUENWALD, J., HALL, T., RIGGINS, C.W. \& RISTER, R.S. 1998. The complete German commission E monographs - therapeutic guide to herbal medicines. American Botanical Council, Austin.

BROOKS, J.S. \& FEENY, P. 2004. Seasonal variation in Daucus carota leaf-surface and leaf-tissue chemical profiles. Biochemical Systematics and Ecology 32:769-782.

BRUYNE, T., PIETERS, L., DEELSTRA, H. \& VLIETINCK, A. 1999. Condensed vegetable tannins: biodiversity in structure and biological activities. Biochemical Systematics and Ecology 27:445-459.

BUKATSCH, F. 1972. Bemerkungen zur Doppelfärbung Astrablau-safranin. Mikrokosmos 61:255.

BUSSOTTI, F., GRAVANO, E., GROSSONI, P. \& TANI, C. 1998. Occurrence of tannins in leaves of beech trees (Fagus sylvatica) along an ecological gradient, detected by histochemical and ultrastructural analyses. New Phytologist 138:469-479.

CONDE, C., DELROT, S. \& GERÓS, H. 2008. Physiological, biochemical and molecular changes occurring during olive development and ripening. Journal of Plant Physiology 165:1545-1562.

FALLEH, H., KSOURI, R., CHAIEB, K., KARRAYBOURAOUI, N., TRABELSI, N., BOULAABA, M. \& ABDELLY, C. 2008. Phenolic composition of Cynara cardunculus L. organs, and their biological activities. Comptes Rendus Biologies 331:372-379.

FRATIANNI, F., TUCCI, M., PALMA, M., PEPE, R. \& NAZZARO, F. 2007. Polyphenolic composition in different parts of some cultivars of globo artichoke (Cynara cardunculus L. var scolymus). Food Chemistry 104:1282-1286.

FREIXA, B., VILA, R., VARGAS, L., LOZANO, N., ADZET, T. \& CAÑIGUERAL, S. 1998. Screening for antifungal activity of nineteen Latin American plants. Phytotherapy Research 12:427-430. 
JOACHIMOVITS, R. 1959. Estudo farmacológico da ação anti-hemorrágica de Polygonum acre H. B. K. Medicina Cirúrgica Farmacêutica 278:216-234.

JOHANSEN, D. 1940. Plant microtechnique. McGraw Hill, New York.

JOLY, A.B. 1976. Botânica: introdução à taxonomia vegetal. Companhia Editora Nacional, São Paulo.

KOTT, V., BARBINI, L., CRUAÑES, M., MUÑOZ, J.D., VIVOT, E., CRUAÑES, J., MARTINO, V., FERRARO, G., CARVALLARO, L. \& CAMPOS, R. 1999. Antiviral activity in Argentine medicinal plants. Jounal of Ethnopharmacology 64:79-84.

KRAUS, J.E. \& ARDUIN, M. 1997. Manual básico de métodos em morfologia vegetal. Editora Universidade Rural, Seropédica.

KUBITZKI, K. \& GOTTLIEB, O.R. 1984. Phytochemical aspects of angiosperm origin and evolution. Acta Botanica Neerlandica 33:457-468.

LERSTEN, N.R. \& CURTIS, D. 1992. Foliar anatomy of Polygonum (Polygonaceae): survey of epidermal and selected internal structures. Plant Systematics and Evolution 182:71-106.

LIMA, S.S., ESQUIBEL, M.A., HENRIQUES, A.B., SILVA, F.O., SILVA, P.H.B. \& LAGE, C.L.S. 2001. Cultura monoclonal da erva-de-bicho (Polygonum acre H. B. $\mathrm{K}$. var aquatile) para produção de um fitoterápico em escala comercial. Revista Brasileira de Plantas Medicinais / Brazilian Journal of Medicinal Plants 4:51-55.

LU, F.J., ZHU, L.T., HOU, Y.T. \& LI, F.Z. 2007. Leaf lower epidermal micro-morphology of Chinese Polygonum section Avicularia. Acta Botanica Boreali Occidentalia Sinica 27:464-468.

MA, M., HONG, C., AN, S. \& LI, B. 2003. Seasonal, spatial, and interspecific variation in quercetin in Apocynum venetum and Poacynum herdersonii, chinese traditional herbal teas. Journal of Agriculture, Food and Chemistry 51:2390-2393.

MACHADO, O.X.B. 1949. Polygonum acre (erva-de-bicho ou catáia). Rodriguésia 24:33-37.

MACLEAN, R.C. \& IVEMEY-COOK, W.R. 1958. Plant science formulae. Macmillan \& Co. Ltd, New York.

MEISNER, C.F. 1855. Polygonaceae. In Flora Brasiliensis (C.F.P. Martius \& A.G. Eichler, eds.). v.5, Parte I, p.18-19.

MELO, J.G., NASCIMENTO, V.T., AMORIM, E.L.C., ANDRADE LIMA, C.S. \& ALBUQUERQUE, U.P. 2004. Avaliação da qualidade de amostras comerciais de boldo (Peumus boldus Molina), pata-de-vaca (Bauhinia spp.) e ginkgo (Ginkgo biloba L.). Revista Brasileira de Farmacognosia 14:111-120.

METCALFE, C.R. 1979. Secreted mineral substances crystals. In Anatomy of dicotyledons. Systematic anatomy of leaf and stem, with a brief history of the subject (C.R. Metcalfe \& L. Chalk, eds.). Clarendon Press, Oxford. v.2, p.82-97
METCALFE, C.R. \& CHALK, L. 1950. Anatomy of dicotyledons: leaves, stem and wood in relation to taxonomy with notes on economic uses. Clarendon Press, Oxford.

MITCHELL, R.S. 1971. Comparative leaf structure of aquatic Polygonum species. American Journal of Botany 58: 342-360.

NEWALL, C.A., ANDERSON, L.A. \& PHILLIPSON, J.D. 2002. Plantas medicinais - Guia para o profissional de saúde. Premier, Londres.

PIO CORRÊA, M. 1984. Dicionário das plantas úteis do Brasil e das exóticas cultivadas. Imprensa Nacional, Ministério da Agricultura, Instituto Brasileiro de Desenvolvimento Florestal, Rio de Janeiro.

SASS, J.E. 1951. Botanical microtechnique. The Iowa State University Press, Ames.

SCHLICHTING, C.D. 1986. The evolution of phenotypic plasticity in plants. Annual Review of Ecology and Systematics 17:667-693.

SCHMITZ, W., SAITO, A.Y., ESTEVÃO, D. \& SARIDAKIS, H.O. 2005. O chá verde e suas ações como quimioprotetor. Semina: Ciências Biológicas e da Saúde 26:119-130.

SCHWEITZER, J.A., MADRITCH, M.D., BAILEY, J.K., LEROY, C.J., HAGERMAN, A.N., WOOLEY, S.C., HART, S.C. \& WHITHAM, T.G. 2008. From genes to ecosystems: the genetic basis of condensed tannins and their role in nutrient regulation in a Populus model system. Ecosystems 11:1005-1020.

SILVA-BRAMBILLA, M.G. \& MOSCHETA, I.S. 2001. Anatomia foliar de Polygonaceae (Angiospermae) da planície de inundação do alto Rio Paraná. Acta Scientiarum 23:571-585.

SIMÕES, C.M., RIBEIRO-DO-VALE, R.M., POLI, A., NICOLAU, M. \& ZANIN, M. 1989. The farmacologic action of extracts of Polygonum punctatun Elliot. Journal de Pharmacie de Belgique 44:275-284.

STRASBURGER, E. 1924. Handbook of pratical Botany. George Allen \& Norwin Ltda, London.

TEIXEIRA, A.H., DALOSTO, C., BOLASSEL, C., CHAGAS, A.M., BOTOLUZZI, M.A.P. \& JUCHEM, W.R.C. 1989. Protector effect of Polygonum acre H. B. K. on the artificial pulmorary hemorrhages in mices. Saúde Revista do Centro de Ciências da Saúde da Universidade Federal de Santa Maria 15:105-116.

WATERMAN, P.G. \& MOLE, S. 1994. Analysis of phenolic plant metabolites. Blackwell Scientific Publications, London.

ZHU, L.T., LU, F.J., HOU, Y.T. \& LI, F.Z. 2007a. Micromorphology of leaf epidermis and its taxonomical significance of Polygonum section Cephalophilon in China. Journal of Wuhan Botanical Research 25: 136-142.

ZHU, L.T., LU, F.J., HOU, Y.T. \& LI, F.Z. 2007b. The micromorphology of leaf lower epidermis of Polygonum section Aconogonon and Koenigia from China. Bulletin of Botanical Research 27:679-686. 